\title{
Reintroduction of Tigridiopalma magnifica, a rare and Critically Endangered herb endemic to China
}

\author{
Hai Ren, Songuen Zeng, Longna Li, Qianmei Zhang, Long Yang, Jun Wang \\ ZHENGFEn WANG and Qinfeng GUo
}

\begin{abstract}
Tigridiopalma magnifica, a perennial herb and the only species in the genus Tigridiopalma (Family Melastomataceae) is rare and endemic to China where it is categorized as Critically Endangered on the national Red List. Twelve locations with populations of T. magnifica have been identified ( 1 extinct, 11 extant). T. magnifica only grows in the surface soil on stone walls or rocks under the canopy of secondary forests and plantations and has no specific associated plant species. Canopy closure, soil water content and the distance to the closest stream are the main factors influencing the distribution of $T$. magnifica. We reintroduced T. magnifica plantlets produced by tissue culture into three locations: one within the species' original range, and 11.5 and $400 \mathrm{~km}$ from the species' original range. After 11 months survival rate was $40-58 \%$ but survival was higher and plantlet crowns were larger at the location within the species' original range than at the other two sites. The combination of advanced propagation techniques and ecological restoration could facilitate reintroduction and conservation of T. magnifica and other rare and threatened plants. This example of the successful reintroduction of a rare, threatened herb has implications for human-assisted migration and colonization of rare plant species under future climate change scenarios.
\end{abstract}

Keywords Canonical Correspondence Analysis, CCA, China, distribution, endemic, habitat, Melastomataceae, Tigridiopalma magnifica

This paper contains supplementary material that can be found online at http://journals.cambridge.org

\section{Introduction}

$\mathrm{P}$ lant species are being lost at an unprecedented rate because of human disturbance (Alcamo \& Bennett,

Hai Ren (Corresponding author)*, SongJun ZenG*, Longna LI, QIANMEI Zhang, Long YANG, JUN WANG and Zhengfeng WANG Key Laboratory of Vegetation Restoration and Management of Degraded Ecosystems, South China Botanical Garden, Chinese Academy of Sciences, Guangzhou 510650, China. E-mail renhai@scib.ac.cn

QINFENG GUo USDA Forest Service, Eastern Forest Environmental Threat Assessment Center, Asheville, North Carolina, USA

${ }^{*}$ Contributed equally to this work

Received 24 September 2010. Revision requested 11 February 2011. Accepted 9 March 2011
2003). At a time of rapid global change the increasing loss of plant diversity requires urgent conservation and restoration efforts (IUCN, 1998). The introduction and reintroduction of species to the wild, especially of species that are rare and threatened, has become an important tool for biodiversity conservation (Akeroyd \& Jackson, 1995; Armstrong \& Seddon, 2008). Reintroduction of plants is the controlled placement of plant material into a natural or managed ecological setting (Akeroyd \& Jackson, 1995). Related terms include introduction, restitution, translocation, reinforcement and restoration (Maunder, 1992; Akeroyd \& Jackson, 1995; SER, 2002; Bajomi et al., 2010). Translocation is a type of reintroduction in which material is transferred from one location to either existing or new locations within the species range (Akeroyd \& Jackson, 1995). Target 8 of the Global Strategy for Plant Conservation describes ex situ conservation and recovery plans for threatened species, with the goal of reintroducing c. $10 \%$ of such plant species to wild habitats (BGCI, 2003).

Successful plant reintroduction requires knowledge of the life history, demography, reproductive biology, horticulture, ecology and geography of the focal species (IUCN, 1998; Armstrong \& Seddon, 2008; Bajomi et al., 2010). There have been a small number of successful reintroductions of shrubs and herbs and an even smaller number involving trees. The poor success rate of reintroductions has led to calls for greater monitoring and biological and ecological studies (Griffith et al., 1989; Armstrong \& Seddon, 2008). Studies of plant reintroduction have typically focused on monitoring establishment rather than on explaining why establishment succeeds or fails (Armstrong \& Seddon, 2008). Horticultural techniques have also been applied to reintroductions (Ren et al., 2010).

The study reported here concerns the herb Tigridiopalma magnifica, the only species in its genus (Family Melastomataceae; Zhang \& Miao, 1984). The species was first discovered and named in 1979; it is endemic to southern China and has a very restricted distribution (Chen, 1979). Because of human disturbance and habitat fragmentation the abundance of T. magnifica has decreased dramatically in the past 30 years. It is estimated that there are no more than 2,000 individuals in the wild, with a core distribution area of $<_{1} \mathrm{~km}^{2}$ (Wang et al., 2004). T. magnifica is categorized as Critically Endangered on the IUCN Red List of China (Xin, 2005) but has not been assessed for the global IUCN Red List (although as the species is endemic its national and global status will be identical). This herb also has potential as an 
indoor ornamental plant because it is tolerant of shade and has attractive leaves and flowers. It flowers from August to December and sets fruit from March to May (Zeng, 2005). T. magnifica has a very specialized habitat, growing only on wet granitic rocks under the forest canopy. In addition, the species is difficult to propagate artificially (Wang et al., 2004). Previous research on T. magnifica has examined its taxonomy and demography (Zhang \& Miao, 1984), distribution (Wang et al., 2004), life history and the obstacles to successful reproduction ( $\mathrm{Li}, 2009)$, the feasibility of tissue culture (Zeng et al., 2008) and its potential as an ornamental (Zeng, 2005).

Here we summarize the results of a 7 -year reintroduction study of T. magnifica. We also describe its distribution, the structure of the plant communities in which it resides, and the major environmental variables that may affect attempts to reintroduce the species. We focus in particular on the following questions: (1) What characterizes the communities in which T. magnifica resides? (2) What are the most appropriate habitats for future reintroductions? (3) What can be done to increase the probability that reintroduced T. magnifica will survive?

\section{Study area}

The study was conducted at Xinyi, Yangchun, Gaozhou and Lianzhou cities in south-west Guangdong Province, southern China. The first three locations lie within the historical and current distribution of T. magnifica, where the climate is subtropical monsoon, altitudes are $60-1,000 \mathrm{~m}$, mean annual temperature is $22.1^{\circ} \mathrm{C}$ and, mean annual total rainfall is 2,300 mm (c. $80 \%$ of which falls in April-October), the soil is lateritic and the vegetation is dominated by evergreen broad-leaved forests typical of the subtropics (Wang et al., 2004). The climate of Lianzhou, which is outside the species' original range, is central subtropical monsoon, altitudes are $130-450 \mathrm{~m}$, mean annual temperature is $19.5^{\circ} \mathrm{C}$, mean annual rainfall $1,571 \mathrm{~mm}$, the soil is lateritic and the vegetation is dominated by evergreen broad-leaved forests typical of the subtropics (Ren et al., 2010).

\section{Methods}

Examination of herbarium specimens and wild populations

We examined all T. magnifica specimens in the four major herbaria of the Chinese Academy of Sciences (Institute of Botany in Beijing, PE; Guangxi Institute of Botany, IBK; Kunming Institute of Botany, KUN; South China Botanical Garden, IBSC). The T. magnifica specimens in these herbaria were collected in 1931, 1935, 1951, 1956, 1957 and 2001. In addition we examined the Flora of China (Flora of China Editorial Committee, 1984) and Flora of Guangdong (Wu,
2005). We interviewed elders in the villages within the range of T. magnifica to obtain information about the past distribution of T. magnifica and associated species, and during 2002-2009 we made several field trips to search for the species.

\section{Vegetation survey}

To examine the vegetation and environment of the natural habitat of $T$. magnifica we used the information from herbarium records and local floras to establish permanent plots, during 2002-2009, in 11 locations where we located wild T. magnifica (Fig. 1; see also Results). In each location we established a nested set of plots in an area of $800 \mathrm{~m}^{2}$ : eight plots of $10 \times 10 \mathrm{~m}$ within each of which we surveyed the tree layer; in four of these plots we established a subplot of $5 \times 5 \mathrm{~m}$, in each of which we surveyed the shrubs; and in three subplots we established a quadrat of $1 \times 1 \mathrm{~m}$ within which we surveyed the herbaceous plants (there were 33 quadrats in all: three in each of the 11 locations). The location, elevation, and aspect of each quadrat were recorded with a global positioning system. In each plot, subplot and quadrat the name, height, diameter at breast height $(\mathrm{DBH})$ and crown size of all plant species were recorded. In each site canopy closure was measured 15 times on two mornings by CID-110 canopy analysis. These vegetation surveys were conducted in April 2004 and March 2009 but as the two sets of data were similar we used only the data from March 2009.

\section{Soil analysis}

We collected soil samples in March 2009 from five random points in each of the 33 quadrats using a 5 - $\mathrm{cm}$ diameter soil corer, to a depth of $5 \mathrm{~cm}$ (the soil layer on the rocks is thin). After mixing the soil samples from the five points in each quadrat we extracted a $0.5-\mathrm{kg}$ subsample for analysis. The 33 subsamples were air-dried and sieved for determination of water content ( $\mathrm{g}$ of water per $100 \mathrm{~g}$ of dry soil); $\mathrm{pH}$ (1:2.5 soil water extracts); $\mathrm{N}$ (decomposed with $\mathrm{NaOH}$, absorbed with boracic acid, titrated with hydrochloric acid); $\mathrm{P}$ (extracted with $\mathrm{HCl} / \mathrm{NH}_{4} \mathrm{~F}$, analysed with a spectrophotometer); $\mathrm{K}$ (extracted with $\mathrm{CH}_{3} \mathrm{COONH}_{4}$, analysed by atomic absorption spectrophotometry); $\mathrm{Ca}, \mathrm{Mg}$ and $\mathrm{Na}$ content (extracted with $\mathrm{H}_{2} \mathrm{SO}_{4} / \mathrm{HClO}_{4}$, analysed by inductively coupled plasma mass spectrometry); and soil organic matter content (digested with $\mathrm{H}_{2} \mathrm{SO}_{4} / \mathrm{K}_{2} \mathrm{Cr}_{2} \mathrm{O}_{7}$, titrated with $\mathrm{FeSO}_{4}$; Standford \& English, 1949; Olsen et al., 1954; Institute of Soil Science \& CAS, 1978; MEWAM, 1986).

\section{Propagation of T. magnifica and preliminary experimentation}

We established a system for in vitro propagation and plant regeneration (Plate 1) using biotechnology developed at the 

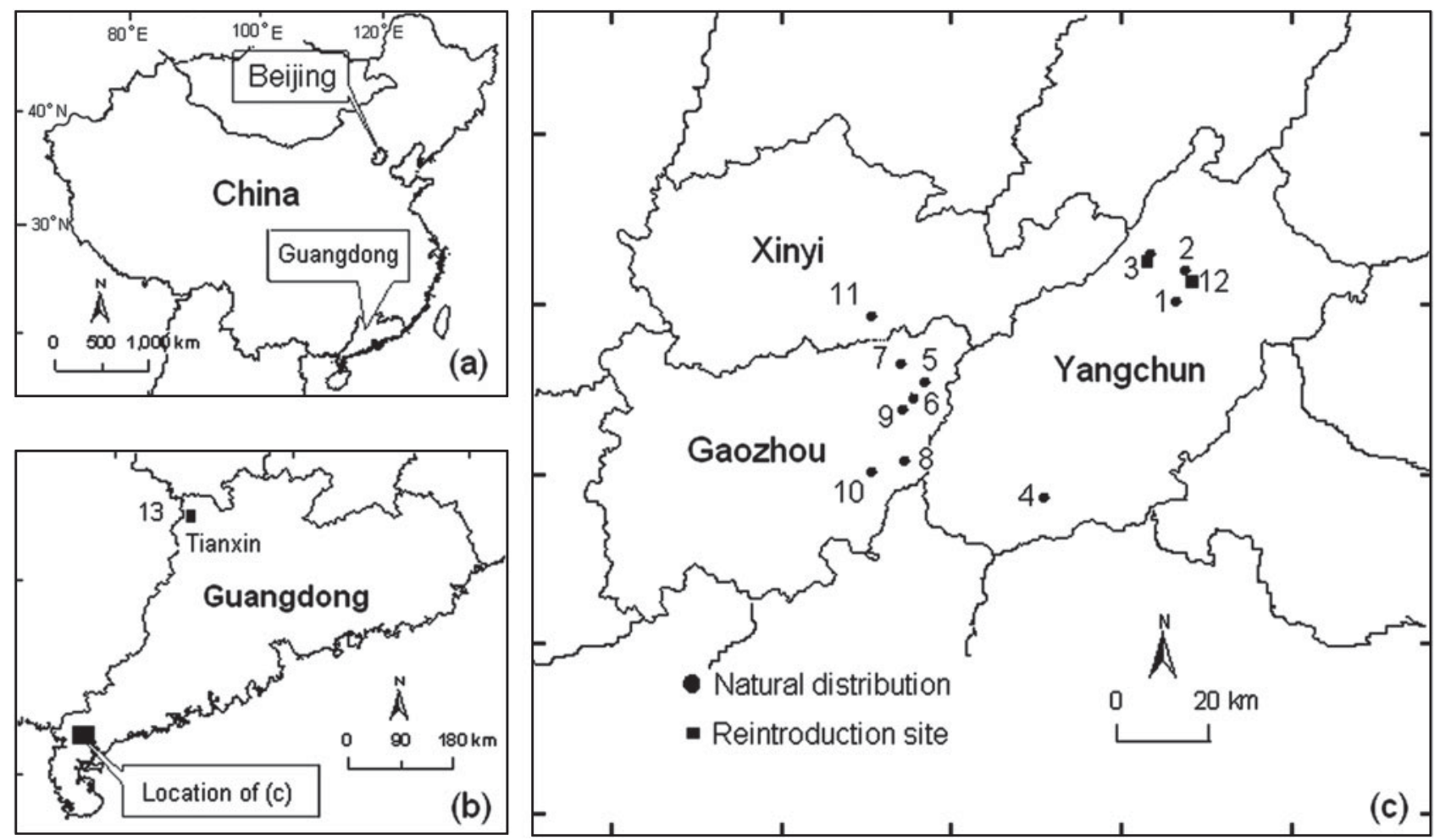

(c)

FIG. 1 The current distribution of Tigridiopalma magnifica and the locations of the vegetation and environment surveys, and of the augmentation, reintroduction and introduction: (a) China, showing the location of Guangdong province, (b) Guangdong Province, showing the location of Tianxin (13, the introduction site) and map (c), and (c) the current distribution (sites 1-11) and augmentation (3) and reintroduction (12) sites. The locations are (1) Dahe, (2) Hepin, (3) Dajiangkou, (4) Chaotang, (5) Muchong, (6) Bankeng, (7) Shachun, (8) Hekeng, (9) Kengchang, (10) Mugengtou, (11) Dongtang, (12) Ehuangzhang and (13) Tianxin.
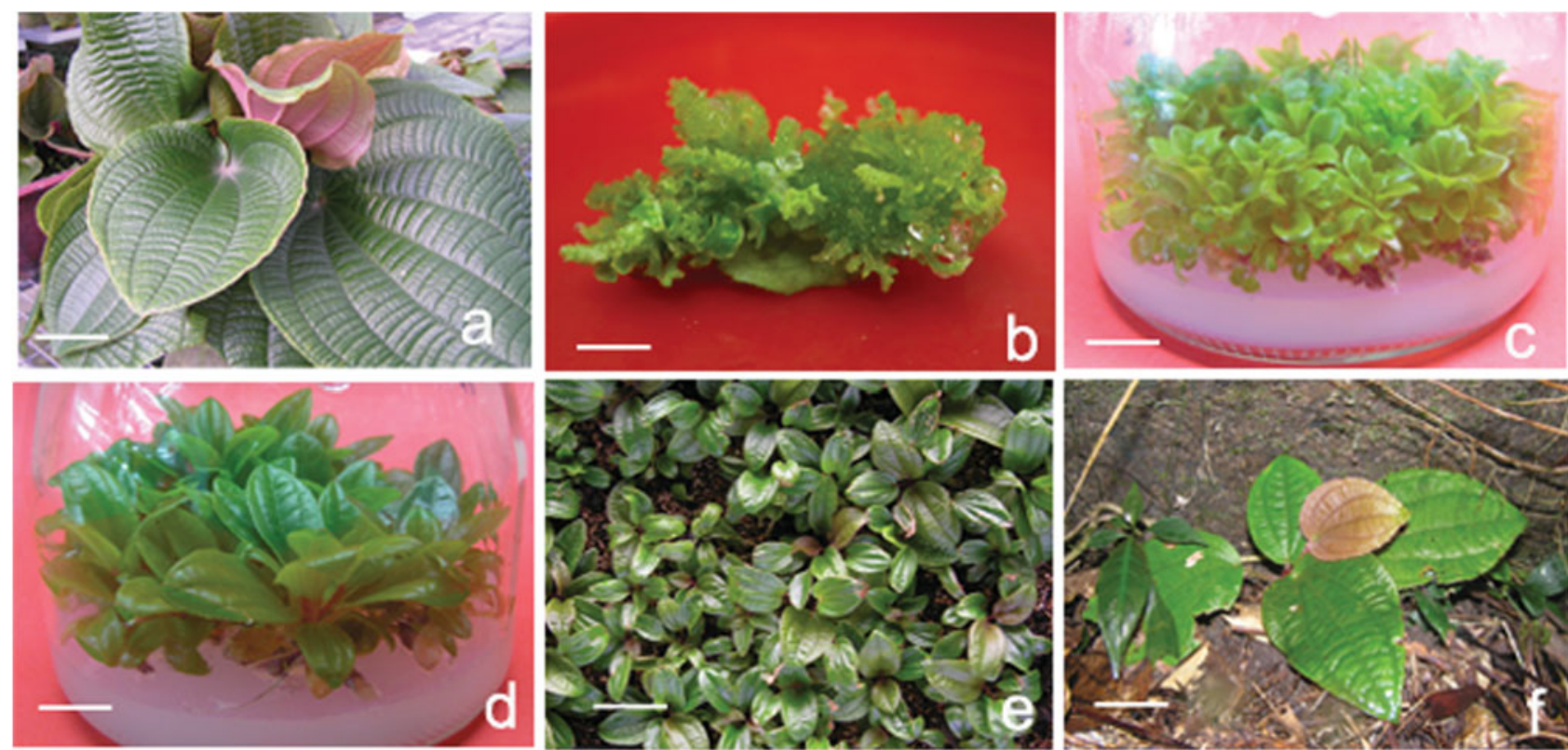

Plate 1 Tissue-culture propagation and reintroduction of Tigridiopalma magnifica: (a) specimen, (b) shoot induced from a leaf explant, (c) shoot proliferation, (d) roots induced, (e) plantlets for transplantation, and (f) reintroduced individuals. The bar in the left corner of each photograph is (a) $10 \mathrm{~cm},(\mathrm{~b}) 0.5 \mathrm{~cm},(\mathrm{c}-\mathrm{d}) 1 \mathrm{~cm}$, and $(\mathrm{e}-\mathrm{f}) 5.0 \mathrm{~cm}$.

South China Botanical Garden. Plantlets were produced from leaf explants following procedures in Zeng et al. (2008). Before attempting to reintroduce T. magnifica we conducted a preliminary experiment to determine how to increase the survival of transplanted plantlets. We transplanted plantlets (kept in vitro for 10-12 months) into a 
planting bed (containing a sterilized mixture of sand, vermiculite, limestone and rice soil) in the greenhouse of the South China Botanical Garden. The plantlets were kept in the greenhouse planting bed for 8-10 months before they were transplanted to a location in the Garden. Survival of plantlets was highest if they were kept in vitro for 12 months and if they were kept in the greenhouse planting bed for a 9-month acclimation period before transplanting into the Garden. In addition we transplanted some plantlets under the forest canopy at five locations that were similar to the habitat of the original distribution of the species. However, the plantlets only survived at three of the locations (see below), and we used these as the reintroduction sites.

\section{Reintroduction trial}

Following the preliminary propagation experiment we planted T. magnifica in three locations: Dajiangkou Village $\left(21^{\circ} 55^{\prime} \mathrm{N}, 1_{111^{\circ}} 30^{\prime}\right.$ E) in Yangchun City, Ehuangzhang Village $\left(22^{\circ} 20^{\prime} \mathrm{N}, 111^{\circ} 46^{\prime} \mathrm{E}\right)$ in Yangchun City, and Tianxin Forestry Farm $\left(25^{\circ} 6^{\prime} \mathrm{N}, 112^{\circ} 21^{\prime} \mathrm{E}\right)$ in Lianzhou City. The first location is an augmentation as individuals were planted within an extant population. The second location is a reintroduction as it is within the historical range of the species but had no extant population. The third location is an introduction as it is outside the species' known historical range. The structure of the plant community at the Tianxing Forestry Farm is similar to that at Ehuangzhang Village. The Dajiangkou Village location was also one of the 11 vegetation survey sites (see above); we also carried out the nested vegetation survey in Ehuangzhang Village and Tianxin Forestry Farm.

At each location we established three quadrats of $1 \times 1 \mathrm{~m}$ for the reintroduction. The quadrats at Dajiangkou were c. $3 \mathrm{~m}$ from the wild population but without wild individuals of T. magnifica. The Ehuangzhang location is the herbarium garden of the Ehuangzhang Nature Reserve, c. $11.5 \mathrm{~km}$ from the original wild population. The Tianxin location is c. 400 $\mathrm{km}$ from Ehuangzhang. The habitat conditions at the three locations are similar (Table 1).

The plantlets were transplanted to the three locations on 16 April 2008 (the wet season). At the time of transplantation the area of each plantlet crown was c. $2.7 \mathrm{~cm}^{2}$. A survey of the wild T. magnifica population at Yangchun indicated that the typical density of these wild populations is c. $16 \mathrm{~m}^{-2}$ and we therefore used $15 \mathrm{~m}^{-2}$ as the planting density in the reintroduction. Plantlets were evenly spaced in each $1 \times 1 \mathrm{~m}$ quadrat. Half the soil in each quadrat was the same soil used for acclimation in the greenhouse and half was untreated soil from the particular location. The plantlets were watered on each of the first 3 days after transplantation but not thereafter. The quadrats were not fenced, fertilized or mulched. We checked the survival and crown size of all transplants, and inferred causes of death (i.e. insect defoliation, fungal decay, nutrient deficiency, lack of water, strong radiation) on 16 April 2008, 21 March 2009, and 26 February 2011.

\section{Data analysis}

In the nested vegetation survey we recorded, in addition to T. magnifica, a total of 149 plant species belonging to 71 families (Appendix). We calculated the importance value of each plant species, which is based on the relative density, dominance and frequency of each species in the community, scaling from o to 300 (Krebs, 1985), and constructed a matrix that included the 45 most common plant species and T. magnifica. We also constructed a matrix of the 11 biotic and abiotic variables characterizing each of the 11 survey locations within the original range of the species. Detrended correspondence analysis (DCA), and canonical correspondence analysis (CCA) were used to quantify and describe the structure of the plant community, using $\mathrm{PC}-\mathrm{ORD}_{4}$ (Hill \& Gauch, 1980; ter Braak, 1986; Økland, 1990; Girard et al., 2002; Lachance \& Lavoie, 2008). Major gradients in vegetation composition were identified using DCA. CCA was then used to examine the relationships between vegetation gradients and the abiotic variables (Leps \& Smilauer, 2003). A principal component analysis (PCA) of the environmental variables was calculated, using SPSS v. 11.0 (SPSS, Chicago, USA), to identify any potential clusters of locations. We calculated a one-way ANOVA, with SPSS, to compare the mean crown area and survivorship of the augmented, reintroduced and introduced individuals.

\section{Results}

We found records of T. magnifica in 12 locations but, during 2002-2009, we only located 11 of these. The location where T. magnifica appears to have become extinct is in Dianbai County $\left(20^{\circ} 30^{\prime} \mathrm{N}, 110^{\circ} 10^{\prime} \mathrm{E}\right)$ in the south of Xinyi City and c. $120 \mathrm{~km}$ from Ehuangzhang Nature Reserve. Although there are records of several collections of T. magnifica from this location in 1956 we found neither herbarium specimens nor wild individuals. The 11 extant populations of T. magnifica are in Yangchun, Xinyi and Gaozhou cities (Fig. 1), distributed patchily along the Yunkai and Yunwu Mountains in south-west Guangdong at altitudes of 50$1,000 \mathrm{~m}$.

T. magnifica is currently growing under the canopies of nine secondary natural forests and in two plantations (Cunninghamia lanceolata plantation in Magui and bamboo in Wangsha; Appendix). The population at Dongtang village is the largest and contains $>1,000$ individuals. The other T. magnifica populations contain 98-212 individuals (Table I). In general the number of plant species within the 


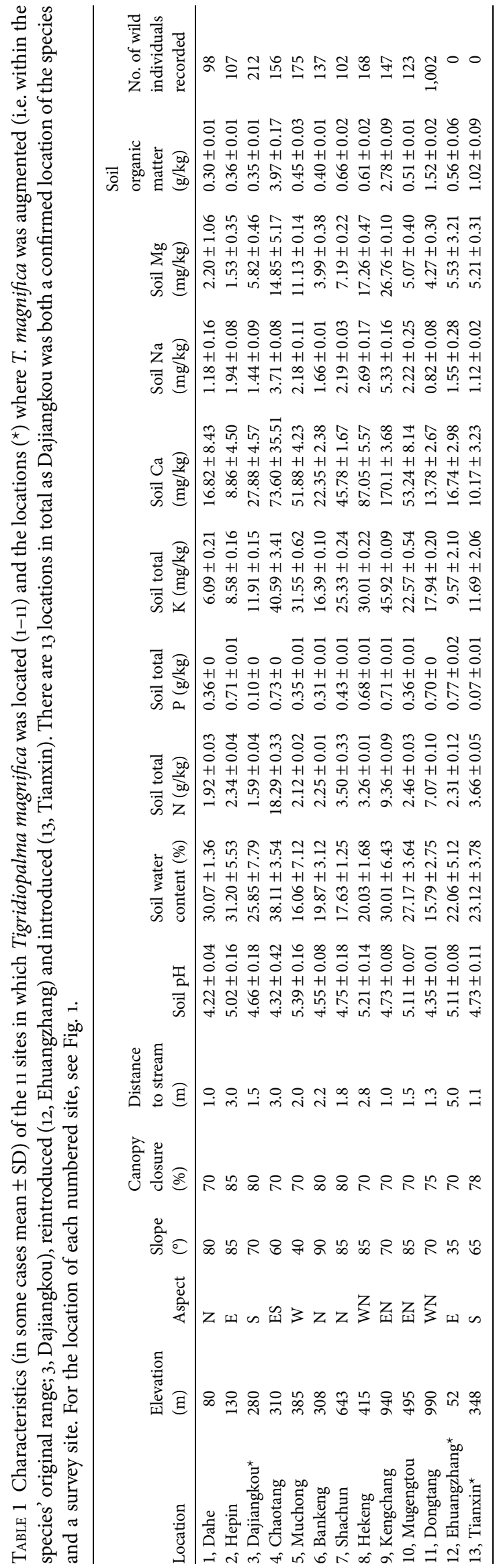

original range of T. magnifica was higher than that in the location used for introduction of T. magnifica (i.e., at Tianxin Forestry Farm, Lianzhou City).

In the DCA ordination the relative positions of the 11 locations within the original range of T. magnifica and the reintroduction and introduction locations indicated the floristic similarity among locations. The first axis explained c. $13.8 \%$ of the total variation in floristic composition. There was no clear separation of locations except for the introduction location (Tianxin). All the wild T. magnifica were growing in soil on stone walls or rocks under the forest canopy. Canopy closure in these locations was $>70 \%$ and the distance of the populations to streams was 1-3 $\mathrm{m}$. The soil nutrient contents are given in Table 1. In the PCA the first four principal components accounted for c. $89 \%$ of the total environmental variation and the first two components $69 \%$. The first component mainly reflected soil nutrients and fertility and the second soil moisture.

In the CCA analysis (Fig. 2) the length of the lines representing the environmental factors represents the degree of correlation with vegetation composition, and the angle and direction of the line represents the relationship. The position of T. magnifica ( $\mathrm{S}_{1}$ in Fig. 2) is closely related to canopy closure, soil water content and distance to streams.

Thirty-four months after transplantation the survival rate was 45,33 , and $33 \%$ at Dajiangkou, Ehuangzhang and Tianxin, respectively (Table 2). The crowns of transplanted plantlets were larger at Dajiangkou than at the other two locations. Although Ehuangzhang lies within the species' historical range and Tianxin does not, the survival rate and crown sizes were similar at these two locations. Although all the surviving individuals had produced seeds by 34 months, germination rate was lower at the reintroduction and introduction locations. Possible causes of transplant mortality were defoliation by the larvae of a noctuid moth, strong radiation, nutrient deficiency and lack of water.

\section{Discussion}

We were able to verify the existence of only 11 populations of T. magnifica, within which individual plants have a patchy, scattered distribution. Ten of the populations were extremely small, with only 98-212 individuals. The population at Dongtang is substantially larger than at the other 10 locations. This location is in a reserve subject to little human disturbance, whereas the other populations are in secondary forests or plantations that often suffer clear cutting or other disturbances. T. magnifica propagates mostly by seeds, which are usually abundant; seed abortion rate is low and germination rate is high (Wang et al., 2004). At the locations 
TABLE 2 Number of individuals and mean crown area of T. magnifica at planting on 16 April 2008, and after 11 months (on 21 March 2009) and 34 months (26 February 2011), with percentage survival at the three locations. Within a line values followed by different letters are significantly different at $\mathrm{P}<0.05$.

\begin{tabular}{|c|c|c|c|c|c|c|c|c|}
\hline \multirow{2}{*}{$\begin{array}{l}\text { Location } \\
\text { (village) }\end{array}$} & \multicolumn{2}{|l|}{ At planting } & \multicolumn{3}{|c|}{ After 11 months } & \multicolumn{3}{|c|}{ After 34 months } \\
\hline & $\begin{array}{l}\text { No. of } \\
\text { individuals }\end{array}$ & $\begin{array}{l}\text { Mean crown } \\
\text { area } \pm S D \\
\left(\mathrm{~cm}^{2}\right)\end{array}$ & $\begin{array}{l}\text { No. of } \\
\text { individuals }\end{array}$ & $\begin{array}{l}\% \\
\text { survival } \pm \text { SD }\end{array}$ & $\begin{array}{l}\text { Mean crown } \\
\text { area } \pm S D \\
\left(\mathrm{~cm}^{2}\right)\end{array}$ & $\begin{array}{l}\text { No. of } \\
\text { individuals }\end{array}$ & $\begin{array}{l}\% \\
\text { survival } \pm S D\end{array}$ & $\begin{array}{l}\text { Mean crown } \\
\text { area } \pm S D \\
\left(\mathrm{~cm}^{2}\right)\end{array}$ \\
\hline Dajiangkou & 45 & $2.74 \pm 0.08^{\mathrm{a}}$ & 26 & $58.7 \pm 7.7^{\mathrm{a}}$ & $4.60 \pm 1.02^{\mathrm{a}}$ & 20 & $44.5 \pm 3.9^{\mathrm{a}}$ & $24.92 \pm 4.25^{\mathrm{a}}$ \\
\hline Ehuangzhang & 45 & $2.72 \pm 0.09^{\mathrm{a}}$ & 18 & $40.0 \pm 6.7^{\mathrm{b}}$ & $3.84 \pm 0.07^{\mathrm{a}}$ & 15 & $33.3 \pm 6.7^{\mathrm{b}}$ & $22.37 \pm 5.34^{\mathrm{a}}$ \\
\hline Tianxin & 45 & $2.72 \pm 0.04^{\mathrm{a}}$ & 19 & $42.2 \pm 11.1^{\mathrm{ab}}$ & $3.87 \pm 1.12^{\mathrm{a}}$ & 10 & $33.3 \pm 10.5^{\mathrm{b}}$ & $23.43 \pm 3.69^{\mathrm{a}}$ \\
\hline
\end{tabular}

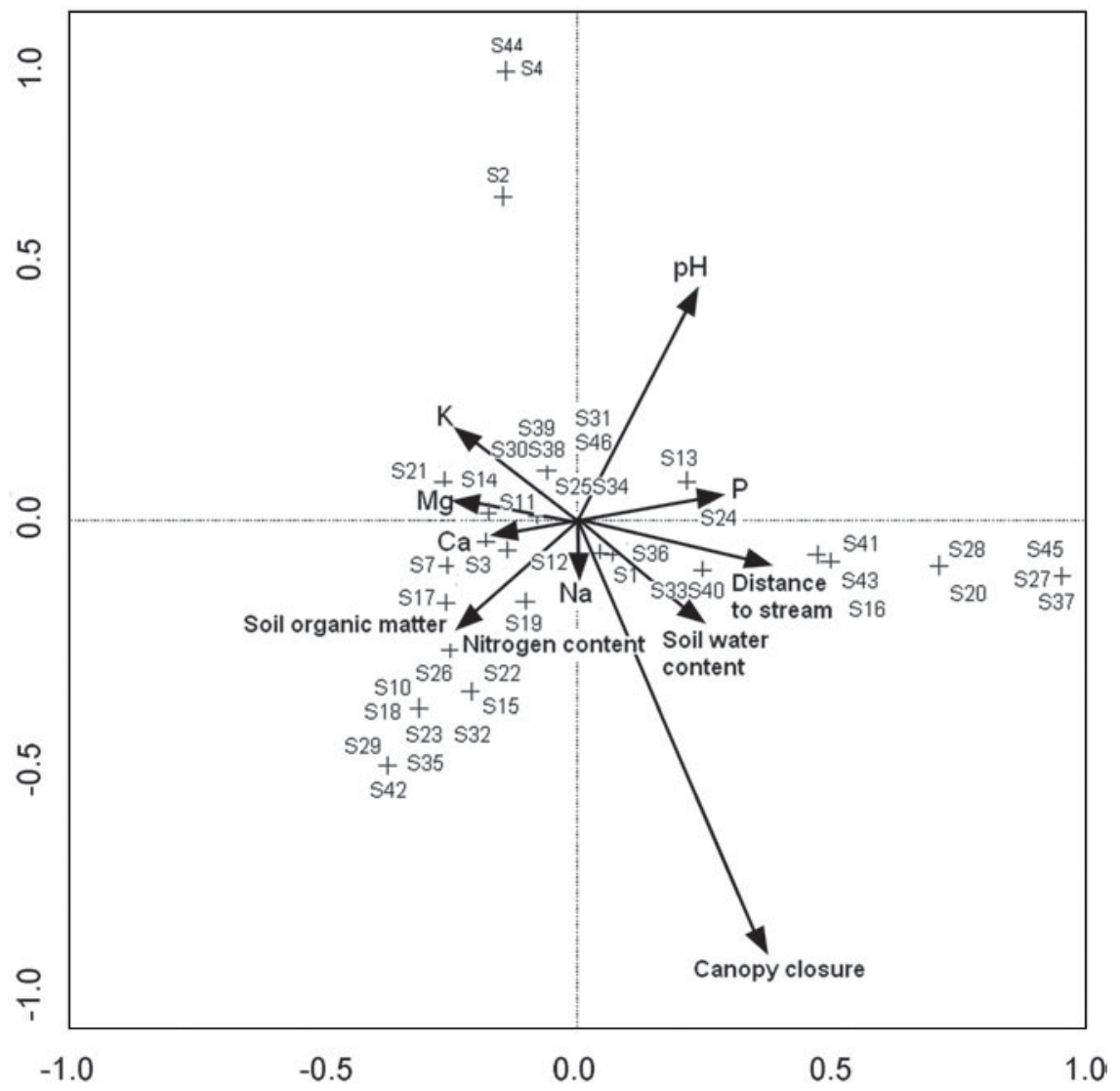

FIG. 2 Results of the canonical correspondence analysis of the vegetation and environmental variables at the 11 locations (Table 1) surveyed within the original range of T. magnifica (labelled $\left.\mathrm{S}_{1}\right)$. The species codes $\left(\mathrm{S}_{2}-\mathrm{S}_{46}\right)$ are detailed in the Appendix. used for reintroduction and introduction, however, survival rate was low and thus constrains natural regeneration (Zeng et al., 2008).

T. magnifica has large and membranous leaves and our results suggest that it grows only under the canopy of forests or plantations and near streams, and requires low temperatures, high humidity and low light. It has strong, fibrous roots and can grow in the thin soil on stone walls and rocks. A species will have difficulty dispersing into the surrounding habitat if it is not competitive in that habitat (Medail \& Verlaque, 1997) and it is possible that T. magnifica grows only on stone walls or rocks because it is not competitive elsewhere. It apparently has an efficient mechanism for nutrient cycling: it does not drop its leaves until they are completely withered and presumably most nutrients have been reabsorbed, and fallen leaves form a litter layer adjacent to the plant.

One of the criteria for the successful reintroduction of a species is that the introduced individuals complete their full life cycle and give rise to a self-sustaining, regenerating population. Most reintroduction studies involving woody species have only reported seedling survival because of long regeneration times (Allen, 1988). Mehrhoff (1996) reintroduced 34 endemic plant species in Hawaii but 8 years later only three species were growing well. Although we monitored reintroduced plants for only 34 months and did not collect data on the next generation, survival rates of T. magnifica seedlings were high compared with survival rates in other reintroduction studies. However, although we successfully reintroduced greenhouse-grown seedlings the 
best method for the conservation of rare and threatened plants may be in situ preservation. Reintroduction can then be used as a complimentary method for conservation. The survival rate of seedlings of $T$. magnifica after 34 months at Tianxin, outside the species' historical range, was $33 \%$, demonstrating that future human-assisted migration of this species, for example in the face of climate change, is possible.

In summary, successful reintroduction of T. magnifica requires a habitat with $>70 \%$ canopy cover, a thin layer of soil on rock, and a nearby stream that is sufficiently close to maintain high soil moisture and humidity. Because propagation of seedlings of T. magnifica is difficult we used a tissue culture technique to produce plantlets. We suggest integrating tissue culture (and perhaps other advanced propagation techniques) with ecological restoration techniques to increase the chances of successful reintroduction of T. magnifica and other threatened plant species. This example of the successful reintroduction of a rare, threatened herb has implications for human-assisted migration and colonization of rare plant species under future climate change scenarios.

\section{Acknowledgements}

This research was supported by the National Science Foundation of China (reference 31170493), Guangzhou Science and Technology Plan (reference 2010U1-E00601), and the Guangdong Sci-Tech Planning Project (reference 2010B060200039). We thank Yizhi Zhuang and Zhixin Tang for field monitoring, Huilan Zhang for soil analysis, HuaguYe for species identification, Jinping Zhang and Linjun Li for mapping and calculations, Bruce Jaffee for help with English and Jennifer Togerson for editing, and two anonymous reviewers for their valuable comments.

\section{References}

Akeroyd, J. \& Jackson, P.W. (1995) A Handbook for Botanical Gardens on the Reintroduction of Plants to the Wild. Botanical Gardens Conservation International and IUCN. Http://www.bgci. org [accessed August 2009].

Alcamo, J. \& Bennett, E.M. (2003) Millennium Ecosystem Assessment. Ecosystems and Human Well-being: A Framework for Assessment. Island Press, Washington, DC, USA.

Allen, W.A. (1988) Biocultural restoration of a tropical forest: architects of Costa Rica's emerging Guanacaste National Park plan to make it an integral part of local culture. Bioscience, 38 , $156-161$.

Armstrong, D.P. \& Seddon, P.J. (2008) Directions in reintroduction biology. Trends in Ecology and Evolution, 23, 20-25.

Bajomi, B., Pullin, A.S., Stewart, G.B. \& Takács-Sánta, A. (2010) Bias and dispersal in the animal reintroduction literature. Oryx, $44,358-365$.
BGCi (Botanical Garden Conservation International) (2003) Global Strategy for Plant Conservation. Http://www.bgci.org [accessed May 2003].

Chen, J. (1979) A new gunus Tigridiopalma C. Chen of Melastomataceae. Acta Botanica Yunnanica, 1, 106-109.

Flora of China Editorial Committee (1984) Flora of China. Science Press, Beijing, China.

Girard, M., Lavoire, C. \& Theriault, M. (2002) The regeneration of a highly disturbed ecosystem: a mined peatland in southern Quebec. Ecosystems, 5, 274-288.

Griffith, B., Scott, J.M., Carpenter, J.W. \& Reed, C. (1989) Translocation as a species conservation tool: status and strategy. Science, 245, 477-480.

Hill, M.O. \& GaUch, H.G. (1980) Detrended correspondence analysis: an improved ordination technique. Vegetatio, 42, 47-58.

Institute of Soll Science \& CAS (Chinese Academy of Sciences) (1978) Soil Physical and Chemical Analysis. Shanghai Technology Press, Shanghai, China.

IUCN (1998) Guidelines for Re-introductions. Prepared by the IUCN/Species Survival Commission Reintroduction Specialist Group. Http://www.iucnsscrsg.org [accessed 17 May 2012].

Krebs, C.J. (1985) Ecology: The Experimental Analysis of Distribution and Abundance. 3rd ed.. Harper \& Row, New York, USA.

Lachance, D. \& Lavoie, C. (2008) Vegetation of Sphagnum bogs in highly disturbed landscapes: relative influence of abiotic and anthropogenic factors. Applied Vegetation Science, 7, 183-192.

Leps, J. \& Smilauer, P. (2003) Multivariate Analysis of Ecological Data Using CANOCO. Cambridge University Press, Cambridge, USA.

LI, L.N. (2009) Studies on conservation and sustainable utilization of the endangered plant Tigridiopalma magnifica. MSc thesis, South China Botanical Garden. Chinese Academy of Sciences, Guangzhou, China.

Maunder, M. (1992) Plant reintroduction: an overview. Biodiversity and Conservation, 1, 51-61.

Medail, F. \& Verlaque, R. (1997) Ecological characteristics and rarity of endemic plants from southeast France and Corsica: implications for biodiversity conservation. Biological Conservation, $80,269-281$.

Menrhoff, L.A. (1996) Reintroducing endangered Hawaiian plants. In Restoring Diversity: Strategies for Reintroduction of Endangered Plants (ed. D.A. Falk), pp. 101-120. Island Press, Washington, DC, USA.

MEWAM (Methods for the Examination of Waters and Associated Materials) (1986) Methods for the Determination of Metals in Soils, Sediments and Sewage Sludge and Plants by Hydrochloric-Nitric Acid Digestion. HM Stationary Office, London, UK.

ØKLAND, R.H.A. (1990) Phytoecological study of the mire Northern Kisselbergmosen, SE Norway. II. Identification of gradients by detrended (canonical) correspondence analysis. Nordic Journal of Botany, 10, 79-108.

Olsen, S.R., Cole, C.V., Watanabe, F.S. \& Dean, L.A. (1954) Estimation of Available Phosphorus in Soils by Extraction with Sodium Bicarbonate. USDA Circular 939, Washington, DC, USA.

Ren, H., MA, G.H., ZhanG, Q.M., Guo, Q., WANG, J. \& WANG, Z. (2010) Moss is a key nurse plant for reintroduction of the endangered herb, Primulina tabacum Hance. Plant Ecology, 209, $313-320$.

SER (Society for Ecological Restoration) (2002) The Society for Ecological Restoration Primer on Ecological Restoration. Http://www.ser.org [accessed 17 May 2012]. 
STANDFORD, S. \& ENGLish, L. (1949) Use of flame photometer for analysis of $\mathrm{Na}, \mathrm{K}$ and $\mathrm{Ca}$. Agronomy Journal, 41, 446-447.

TER BRAAK, C.J.F. (1986) Canonical correspondence analysis: a new eigenvector method for multivariate gradient analysis. Ecology, $67,1167-1179$.

WANG, F.G., YE, H.G. \& YE, Y.S. (2004) The resource and conservation of rare and endangered plants in Ehuangzhang Nature Reserve, Guangdong Province. Journal of South China Agricultural University, 25, 77-79.

Wu, T.L. (2005) Flora of Guangdong. Guangdong Science \& Technology Press, Guangzhou, China.

XIN, F.W. (2005) Rare Plants of China. Hunan Education Press, Changsha, China.

ZENG, S.J. (2005) Rare foliage plants-Tigridiopalma magnifica. Flower Pot and Gardening, 12, 39.

ZENG, S.J., DuAn, J. \& Li, L.N. (2008) Plant regeneration from leaf explants of Tigridiopalma magnifica (Melastomataceae). Pakistan Journal of Botany, 40, 1179-1184

Zhang, H.D. \& Mino, Y.H. (1984) Flora of China. Science Press, Beijing, China.

\section{Appendix}

The Appendix for this article is available online at http:// journals.cambridge.org/orx

\section{Biographical sketches}

This study is a collaboration between five research groups at two institutions and in a wide range of disciplines. H A REN is interested in vegetation restoration and reintroductions of rare and threatened plant species. SONGJUN ZENG is a biochemist currently involved in plant conservation. LONGNA $L_{I}$ is a technician working on in vitro propagation and plant regeneration. QIANMEI ZHANG is a data analyst with strong interests in long-term ecological studies. LONG YANG specializes in vegetation restoration and horticulture. JUN WANG works on ecological restoration and is interested in seed bank and landscape design. ZHengfeng WANG focuses on plant conservation genetics. Qinfeng Guo's research interests include biological invasions, community ecology and biogeography. 